Hajiashrafi, T.; Salehi, S.; Kubicki, M.; Flanagan, K. J.; Senge, M. O. (2020):

Synthesis, characterization, and crystal structure analysis of $\mathrm{Zn}(\mathrm{II})$ and $\mathrm{Cd}(\mathrm{II})$ coordination compounds containing 4-((pyridin-4ylmethylene)amino)phenol Schiff-base ligand.

Journal of Molecular Structure 1221, 128846. doi: 10.1016/j.molstruc.2020.128846

\title{
Synthesis, characterization, and crystal structure analysis of
}

\section{Zn(II) and Cd(II) coordination compounds containing 4-}

\section{((pyridin-4-ylmethylene)amino)phenol Schiff-base ligands}

Taraneh Hajiashrafi, ${ }^{a}$ Shiva Salehi, ${ }^{a}$ Maciej Kubicki, ${ }^{b}$ Keith J. Flanagan, ${ }^{c}$ Mathias O. Senge, ${ }^{c}$

${ }^{a}$ Department of Chemistry, Faculty of Physics and Chemistry, Alzahra University, PO Box 1993891176, Tehran, Iran

${ }^{b}$ Department of Chemistry, Adam Mickiewicz University, ul. Grunwaldzka 6, 60-780 Poznan, Poland

c School of Chemistry, Trinity Biomedical Science Institute, Trinity College Dublin, The University of Dublin, 152-160 Pearse Street, Dublin 2, Ireland

\begin{abstract}
$\mathrm{Zn}(\mathrm{II})$ and $\mathrm{Cd}(\mathrm{II})$ coordination compounds containing 4-((pyridin-4-ylmethylene)amino)phenol ligands were synthesized and then characterized using spectroscopic techniques and single crystal X-ray crystallography. The molecular structure and crystal packing of these complexes, as well as the packing of related compounds, were investigated using geometrical, Hirshfeld surface analyses, and theoretical calculations. The supramolecular architecture of these coordination complexes is governed by a combination of $\pi \cdots \pi$ stacking, $\mathrm{C}-\mathrm{H} \cdots \pi, \mathrm{O}-\mathrm{H} \cdots \mathrm{N}$, and $\mathrm{C}-\mathrm{H} \cdots \mathrm{X}$ hydrogen bonding interactions. This study provides further insight into the understanding of the coordination chemistry of group IIB containing Schiff-base ligand and the role of weak non-covalent interactions in the solid-state structure of coordination compounds.
\end{abstract}

\section{Keywords:}

Coordination compounds of group IIB; Schiff-base ligand; $\pi$-interactions, metallosupramolecular chemistry 


\section{Introduction}

In the last two decades, the supramolecular chemistry of inorganic compounds has attracted increasing interest because of their fascinating structures and their potential applications in various fields such as catalysis [1], gas storage [2], and molecular recognition [3,4]. It is now well-established that the manner in which molecular building blocks are arranged within supramolecular structures has a tremendous effect on their physical and chemical properties $[5,6]$. In comparison to organic supramolecular chemistry, the prediction of the solid-state structure of metal-containing crystals is more challenging due to the complexity of predicting the structural outcome of the supramolecular architecture [7-9]. In this regard, supramolecular chemists have attempted to understand the rules of supramolecular assembly of metalcontaining compounds by studying the solid-state structures of these systems using X-ray crystallography data to provide a detailed picture of the supramolecular structure $[10,11]$. These studies revealed the roles played by the metal, ligand geometries and denticities [12,13], counter-ions [14,15] and reaction conditions $[16,17]$ in determining the final metallosupramolecular architecture $[18,19]$. Among these, rational selection of the organic ligands plays a decisive role in designing well-defined architectures not only because of their role in directing the dimensionality and topology of the final structure but also due to providing potential interaction sites to generate predefined patterns of intermolecular interactions (synthons) [20-22]. A variety of supramolecular synthons based on highly directional intermolecular interactions such as hydrogen bonding, halogen bonding, and even weak directional $\pi$-stacking interactions have been identified and employed as synthetic vectors for the assembly of metal-containing materials $[23,24]$. It should be noted that although weak interactions such as $\pi$-stacking and non-classical hydrogen bonds are usually regarded as weak intermolecular contacts compared to the classical hydrogen bonds, there is experimental evidence showing these interactions can even affect the coordination geometry of metal complexes [25-29]. Therefore, supramolecular chemists have a large toolbox of functionalities capable of non-covalent interactions at their disposal (supramolecular synthons), which 
allow them to design the metal-containing building blocks into well-defined supramolecular architecture according to the chemical information encoded in their molecular structure $[18,30]$.

As a continuation of our research interest toward the understanding of the supramolecular organization of group IIB coordination compounds [31-33], three new crystal structures, namely $\left[\mathrm{Zn}(\mathrm{L})_{2} \mathrm{Cl}_{2}\right],\left[\mathrm{Cd}(\mathrm{L})_{2} \mathrm{I}_{2}\right]$

and $\left[\mathrm{Cd}(\mathrm{L})_{2} \mathrm{I}_{2}\right] \cdot \mathrm{MeOH}$, containing the 4-((pyridin-4-ylmethylene)amino)phenol ( $\left.\mathrm{L}^{4-\mathrm{OH}}\right)$ ligand were synthesized and then characterized using spectroscopic techniques and single crystal X-ray crystallography. The crystal structures of these complexes, as well as the related compounds, were investigated using geometrical, Hirshfeld surface analyses and theoretical calculations. This study reveals the role of $\pi$-interactions and hydrogen bonds in the organization and stabilization of these metalcontaining crystal structures.

\section{Experimental Section}

\subsection{Apparatus and reagents}

Starting materials for the synthesis of compounds $\mathbf{1}$ and $\mathbf{2}$ were purchased from Aldrich Chemical Company and used without further purification. The Fourier transform infrared spectra were recorded at room temperature on a Nicolet Fourier Transform IR (Nicolet 100 spectrometer) in the range 500-4000 $\mathrm{cm}^{-1}$ using $\mathrm{KBr}$ pellets. Elemental analyses (carbon, hydrogen, and nitrogen) were determined using an ECS 4010 CHN-O made in Costech, Italy. Melting points were measured by an Electrothermal 9100 melting point apparatus and were corrected.

\subsection{Single-Crystal Diffraction Studies}

X-ray diffraction data were collected for $\mathbf{1}$ at 130(1) K on a Rigaku four-circle SuperNova diffractometer with Atlas CCD detector and mirror-monochromated $\mathrm{CuK}_{\alpha}$ radiation $(\lambda=1.54178 \AA$ ); for 2 at $100(1) \mathrm{K}$ on a Rigaku four-circle Xcalibur diffractometer, with Eos CCD detector and graphite-monochromated $\mathrm{MoK}_{\alpha}$ radiation $(\lambda=0.71069 \AA)$, and for 3 at 100(1) K on a Bruker APEX-II four-circle diffractometer, 
with graphite-monochromated $\mathrm{MoK}_{\alpha}$ radiation $(\lambda=0.71069 \AA)$. The data were corrected for Lorentzpolarization as well as for absorption effects [1]. Precise unit-cell parameters were determined by a leastsquares fit of 3293 (1), 11830 (2), and 9793 (3) reflections of the highest intensity, chosen from the whole experiment. The structures were solved with SHELXT-2013 [2] and refined with the full-matrix leastsquares procedure on $\left|\mathrm{F}^{2}\right|$ by SHELXL-2013 [3]. All non-hydrogen atoms were refined with anisotropic thermal parameters, hydrogen atoms were placed in idealized positions and refined as 'riding model' with isotropic displacement parameters set at 1.2 (1.5 for methyl groups) times $U_{\text {eq }}$ of appropriate carrier atoms. In 1 the central $\mathrm{C}-\mathrm{CH}=\mathrm{N}-\mathrm{C}$ group was found disordered over two alternative positions, site occupation factors of 0.5 were ascribed for both sites, Figure S1. The crystallographic information is listed in Table 1 and further experimental and refinement detail can be found in the SI. CCDC-1993550 (for 1), 1993551 (for 2), and 1993553 (for $\mathbf{3}$ ) contains the supplementary crystallographic data for this paper.

Hirshfeld surface analysis and two-dimensional fingerprint plots were generated by using Crystal Explorer 3.1 software [34]. These surfaces visually summarize the spatial arrangement and relevance of intermolecular interactions by their color code.

\subsection{Theoretical methods}

DFT calculations of the non-covalent interactions were carried out using the ORCA quantum chemistry suite [35]. The BLYP exchange-correlation functional [36] with the recent D3 empirical dispersion correction (BLYP-D3) was used to evaluate the binding energies [37]. The basis set superposition error (BSSE) is not taken into consideration because small BSSE effects are assumed to be absorbed by the D3 empirical potential [38]. The decomposition of the interaction binding energy was also computed at BLYP-D3/TZ2P. To evaluate the interactions in the solid-state, we have used the crystallographic coordinates. This procedure and level of the theory have been successfully used to evaluate similar interactions [39-41]. An all-electron triple-zeta basis-set with two polarization functions, TZ2P, has been 
used to describe all the atoms. The core electrons were treated by using frozen core approximation. The zeroth-order regular approximation (ZORA) was applied for treating relativistic effect.

\subsection{Synthesis}

$\left[\mathrm{Zn}(\mathrm{L})_{2} \mathrm{Cl}_{2}\right](\mathbf{1}),\left[\mathrm{Cd}(\mathrm{L})_{2} \mathrm{I}_{2}\right](\mathbf{2})$, and $\left[\mathrm{Cd}(\mathrm{L})_{2} \mathrm{I}_{2}\right] \cdot \mathrm{MeOH}(\mathbf{3})$ were synthesized according to the reported procedure by some of us [32].

\subsection{1 $\left[\mathrm{Zn}(\mathrm{L})_{2} \mathrm{Cl}_{2}\right](1),\left[\mathrm{Cd}(\mathrm{L})_{2} \mathrm{I}_{2}\right](2)$ and $\left[\mathrm{Cd}(\mathrm{L})_{2} \mathrm{I}_{2}\right] . \mathrm{MeOH}(3)$}

To a solution of $0.1 \mathrm{mmol} \mathrm{MX}_{2}(\mathrm{M}=\mathrm{Zn}$ or $\mathrm{Cd} ; \mathrm{X}=\mathrm{Cl}$ or $\mathrm{I})$ in $5 \mathrm{~mL}$ methanol, a solution of $\mathbf{L}(0.1 \mathrm{mmol})$ in $5 \mathrm{~mL}$ of methanol was added with stirring. The mixture was heated at $50{ }^{\circ} \mathrm{C}$ for about 15 minutes, followed by reduction of the solvent volume, resulting in immediate formation of bright yellow solid. Stirring was continued for $10 \mathrm{~min}$ and then the mixture was filtered with a filter paper. The solid residue was washed with a little cold methanol, dried in vacuo and then dissolved in $20 \mathrm{~mL}$ of hot methanol. Upon slow evaporation of the filtrate at room temperature, colorless crystals of $\mathbf{1}$ and $\mathbf{2}$ suitable for X-ray diffraction were collected within a week. Notably, two different crystals were obtained for compound 2 including the yellow prism crystals (2) and colorless block crystals (3). The crystal structure analysis revealed that compound $\mathbf{3}$ was the pseudo-polymorph of compound $\mathbf{2}$. Also, it should be noted that other zinc and cadmium halide complexes with $\mathbf{L}^{4-O H}$ ligand that would have been of interest here could not be studied because no suitable crystals were obtained.

Compound 1 (yield 75\%). Anal. calcd for $\mathrm{C}_{24} \mathrm{H}_{20} \mathrm{Cl}_{2} \mathrm{~N}_{4} \mathrm{O}_{2} \mathrm{Zn}$ : C, 54.11; H, 3.78; N, 10.52. Found: C, 54.18 H, 3.86; N, 10.46. IR (KBr pellet, $\mathrm{cm}^{-1}$ ): 3759(w), 3351(vs), 1619 (vs), 1585(vs), 1503(s), 1429(s), 1373(w), 1334(s), 1267(s), 1206(vs), 1156(w), 1027(m), 837(vs), Figure S2a. Melting Point: 172-173 ${ }^{\circ} \mathrm{C}$.

Compounds 2 and 3 (yield 60\% (2+3)). Anal. calcd for $\mathrm{C}_{24} \mathrm{H}_{20} \mathrm{Cd} \mathrm{I}_{2} \mathrm{~N}_{4} \mathrm{O}_{2}(2)$ : C, 37.80; H, 2.64; N, 7.35. Found: C, 37.78 H, 2.61; N, 7.35. FT-IR (KBr pellet, cm-1): 3444(w), 3423(br), 3139(br), 1614 (s), 
1574(vs), 1540(s), 1509(w), 1458(m), 1423(m), 1376(w), 1284(s), 1238(s), 1160(s), 1010(s), 835(s), 544(w), Figure S2(b) and (c). Melting Point: $177-179{ }^{\circ} \mathrm{C}$.

Compounds 3 (yield 60\% (2+3)). Anal. calcd for $\mathrm{C}_{26} \mathrm{H}_{28} \mathrm{Cd} \mathrm{I}_{2} \mathrm{~N}_{4} \mathrm{O}_{4}(3)$ : C, 37.77; $\mathrm{H}, 3.41 ; \mathrm{N}, 6.78$. Found: C, 37.75 H, 3.45; N, 6.75. FT-IR (KBr pellet, $\mathrm{cm}^{-1}$ ): 3423(br), 3127(br), 1613 (s), 1573 (vs), 1541(s), 1509(w), 1457(m), 1418(m), 1374(w), 1284(s), 1237(s), 1158(s), 1008(s), 834(s), 541(w). Melting Point: $175-177^{\circ} \mathrm{C}$.

\section{Results and Discussion}

\subsection{Synthesis and crystal structure analysis}

Compounds (1) and (2) were synthesized by reacting 4-((pyridin-4-ylmethylene)amino)phenol ligand with the corresponding metal halide salts. Two different crystals were obtained for compound $\mathbf{2}$ from the same growth solution, these entities are referred to as pseudo polymorphs, which is further supported by single crystal X-ray diffraction data. ORTEP drawings of compounds 1-3 which are drawn at 50\% ellipsoid probability level are shown in Figure 1. Selected bond distances and angles are listed in Table 2. In $\mathbf{1}$ and $\mathbf{2}$ the complex molecules are unsymmetrical (however some degree of pseudo-symmetry can be found), so the asymmetric part contains one molecule; in $\mathbf{3}$ the complex is $C_{2}$-symmetrical, central Cd ion lies across crystallographic two-fold axis in the space group $\mathrm{Pba2}$, and only one ligand molecule and one solvent - methanol molecule is symmetry-independent. This last complex is isostructural with $\mathrm{Hg}$ complexes (with I and $\mathrm{Br}$ ) [32]. The molecular structure of all three compounds shows discrete mononuclear four-coordinate zinc(II) or cadmium(II) units, coordinated by two pyridyl nitrogen atoms of two different $\mathrm{L}^{4-\mathrm{OH}}$ ligands and two terminal halide ions. According to the four-coordinate geometry index ( $\left.\tau_{4}\right)$ defined by Houser and his co-workers, within the continuum between square planar $\left(\tau_{4}=0\right)$ and tetrahedral $\left(\tau_{4}=1\right)$, the coordination geometry around $\mathrm{M}(\mathrm{II})$ can be described as tetrahedral (1) and trigonal pyramidal (2 and $\mathbf{3}$ ), with $\tau_{4}$ values of $0.98,0.88,0.73$ for compounds $\mathbf{1}, \mathbf{2}$, and $\mathbf{3}$, respectively [42]. The 
dihedral angle between the planes of phenyl and pyridyl rings of $\mathrm{L}^{4-\mathrm{OH}}$ ligand lies between $5.50-52.81^{\circ}$ and thus the ligand can adjust itself to meet the requirement of coordination geometry of the metal atom and the optimal inter-atomic distances in the crystal structure, Table S1. In this regard, Vittal and his coworkers report the crystal structure of [ $\mathrm{ZnBr}_{2}$ (4-styrylpyridine)2] in which $\mathrm{Zn}(\mathrm{II})$ is in perfect tetrahedral geometry and the dihedral angle between the two aromatic rings of 4-styrylpyridine ligand is similar to that for compound 1 [43]. In $\mathrm{Hg}(\mathrm{II})$ complexes containing substituted styrylpyridine ligand, the two aromatic rings of the corresponding ligand no longer show the large dihedral angle, but instead the two aromatic rings adopt a nearly coplanar geometry [44-46].

In the crystal structure of $\mathbf{1}$, adjacent mononuclear units are linked to each other through a combination of $\pi$-interactions, namely pyridyl $\pi$ - $\pi_{\text {phenyl }}$ stacking (ring centroid to ring centroid distance $=3.753 \AA$ ), pyridylC$\mathrm{H} \cdots \pi_{\text {phenyl, }}$ phemylC-H $\cdots \pi_{\text {pyridyl, }}$ as well as pyridyl $\mathrm{C}-\mathrm{H} \cdots \mathrm{O}$ non-classical hydrogen bonds in the crystallographic $b$-direction. The overall supramolecular structure results from linking the $\left[\mathrm{Zn}(\mathrm{L})_{2} \mathrm{Cl}_{2}\right]$

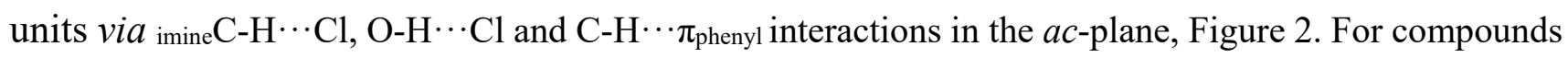
$\mathbf{2}$ and 3, while they are pseudo-polymorphs, they exhibiting both striking similarities as well as some significant differences in their supramolecular structure. In the crystal structure of $\mathbf{2}$, discrete neutral $\left[\mathrm{Cd}(\mathrm{L})_{2} \mathrm{I}_{2}\right]$ units are linked to each other, along the crystallographic $a$-direction, through pyridyl $\pi$ - $\pi_{\text {pyridyl }}$ ( ring centroid to ring centroid distance $=3.975 \AA$ ), pyridylC-H $\cdots \pi_{\text {phenyl }}$ and ${ }^{\cdots} \cdots \pi_{\text {pyridyl }}$ interactions, Table 4 and Figure 3(a). The $\mathrm{O}-\mathrm{H} \cdots \mathrm{N}$, phenylC-H $\cdots \mathrm{O}\left[R_{2}^{2}(8)\right.$ graph set notation $]$ and phenylC-H $\cdots \mathrm{I}$ hydrogen bonds link these units in the $b c$-plane to form the three-dimensional (3D) network, Figure 3(b). Analysis of the

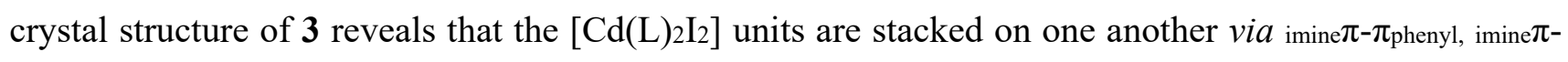
$\pi_{\text {pyridyl }}$ (bond centroid to ring centroid distances of 3.503 and $3.555 \AA$, respectively), and $\mathrm{O}($ lone pair) ${ }^{\cdots} \pi_{\text {phenyl }}$ interactions along the crystallographic $c$-direction, Figure $4(a)$. The methanol molecules of crystallization link discrete molecular units, in the $a b$-plane, via $\mathrm{MeOHO}-\mathrm{H} \cdots \mathrm{N}$ imine and $\mathrm{MeOHC}-\mathrm{H} \cdots \mathrm{OOH}$ 
hydrogen bonds, which is further assisted by imine $\mathrm{C}-\mathrm{H} \cdots \mathrm{I}$ interaction to generate the 3D crystal packing, Table 3, Figure 4(b).

A search in the Cambridge Structural Database (CSD) on the coordination compounds based on (4substituted)-1-(pyridin-4-yl)methanimine ligand returned 13 hits [47]. All of these coordination compounds contain $\mathrm{Hg}(\mathrm{II})$ as metal centers that have different molecular structures and supramolecular features, which are listed in Table 5. These results reveal that the variation of $\mathbf{L}$ ligand para-substituents can have a profound effect on the coordination geometry of metal atom as well as supramolecular arrangement of these coordination compounds. In this regard, the $\left[\mathrm{Cd}\left(\mathrm{L}^{4-\mathrm{F}}\right) \mathrm{I}_{2}\right]$ is a $1 \mathrm{D}$ coordination polymer with the cadmium atom in a distorted octahedral configuration, while both $\left[\mathrm{Cd}\left(\mathrm{L}^{4-\mathrm{OH}}\right) \mathrm{I}_{2}\right]$ polymorphs are discrete coordination complexes in which the cadmium atoms are found in a trigonal pyramidal environment $[48,49]$. Also, the $\left[\mathrm{Hg}\left(\mathrm{L}^{4-\mathrm{OH}}\right) \mathrm{Br}_{2}\right]$ and $\left[\mathrm{Hg}\left(\mathrm{L}^{4-\mathrm{Br}}\right)_{2} \mathrm{Br}_{2}\right]$ are discrete complexes with four-coordinate seesaw geometries for $\mathrm{Hg}(\mathrm{II})$ ions, while $\left[\mathrm{Hg}\left(\mathrm{L}^{4-\mathrm{Cl}}\right) \mathrm{Br} 2\right]$ and $\left[\mathrm{Hg}\left(\mathrm{L}^{4-\mathrm{F}}\right) \mathrm{Br} 2\right],\left[\mathrm{Hg}\left(\mathrm{L}^{4-\mathrm{I}}\right) \mathrm{Br} 2\right]$ are all 1D coordination polymers with a four-coordinate seesaw and five-coordinate square pyramid geometries $[32,48]$. These differences are also observed for the $\left[\mathrm{Hg}\left(\mathrm{L}^{4-\mathrm{OH} / \mathrm{F} / \mathrm{Cl} / \mathrm{Br} / \mathrm{I}}\right)_{2} \mathrm{I}_{2}\right]$ series which the data are presented in Table 5.

\subsection{Hirshfeld surface analysis and theoretical calculation}

Analysis and calculations of the Hirshfeld surface analysis were carried out to analyze the intermolecular contacts present in the crystal packing of coordination compounds 1-3. The Hirshfeld surface analysis is a powerful graphical tool for obtaining additional intuition into the intermolecular contacts in crystalline systems [34]. A bar chart of percentage contributions of the different types of intermolecular contacts and the (2D) fingerprint plots of the coordination compounds are shown in Figures 5, Figure S3 and S4, and Table S2. The Hirshfeld surface analysis and associated fingerprint plots reveal that the crystal packing of compounds 1-3 are supported by $\mathrm{H}^{\cdots} \mathrm{H}, \mathrm{C}-\mathrm{H} \cdots \pi, \mathrm{C}-\mathrm{H} \cdots \mathrm{X}, \mathrm{C}-\mathrm{H} \cdots \mathrm{O}$, and $\pi \cdots \pi$ stacking interactions, 
Figure S4. The $\mathrm{H} \cdots \mathrm{H}$ and $\mathrm{C}-\mathrm{H} \cdots \pi$ intermolecular contacts are the most abundant contacts and play important roles in governing the crystal packing and $\mathrm{C}-\mathrm{H} \cdots \mathrm{X}(\mathrm{X}=\mathrm{Cl}, \mathrm{I}), \mathrm{C}-\mathrm{H} \cdots \mathrm{O} / \mathrm{O}-\mathrm{H} \cdots \mathrm{O}$, and $\pi \cdots \pi$ interactions are the next priorities, respectively. The small contribution from the other interatomic contacts, namely $\mathrm{N}^{\cdots} \pi$ to the Hirshfeld surface of compounds 1-3 listed in Table S2, show negligible influence upon the packing. The large contribution for the van der Waals $\mathrm{H} \cdots \mathrm{H}$ interactions is typical of organic molecules and is consistent with the presence of $\mathrm{CH}$ groups along the ligand backbone [50]. The comparison of the Hirshfeld surfaces of compounds $\mathbf{2}$ and $\mathbf{3}$ reveals that in the crystal structure of $\mathbf{2}$ the $\mathrm{C}-\mathrm{H} \cdots \pi$ interaction is dominant to the $\mathrm{C}-\mathrm{H} \cdots \mathrm{I}$ interaction, while this is vice versa for 3 .

The theoretical study is devoted to analyzing the non-covalent interactions that direct the self-assembly of coordination compounds 1-3 in the solid-state, focusing our attention to the $\mathrm{C}-\mathrm{H} \cdots \mathrm{X}$ hydrogen bonding, $\mathrm{C}-\mathrm{H} \cdots \pi$, and $\pi-\pi$ stacking interactions. The binding energies obtained from the BLYP-D3 calculation on two relative fragments provide us with an opportunity to evaluate the intermolecular contacts between $\left[\mathrm{MLX}_{2}\right]$ molecular units, Tables 3 and 4 . The selected fragments were cut out directly from the CIF file and are shown in Figure S5. The energies of intermolecular interactions are in the range of those found for a series of neutral complexes $[28,39,51]$. The non-classical $\mathrm{C}-\mathrm{H} \cdots \mathrm{X}$ and $\mathrm{C}-\mathrm{H} \cdots \mathrm{O}$ and classical O$\mathrm{H} \cdots \mathrm{N}$ hydrogen-bonding energies in compound 2 calculated to be in the range of $3.20-10.20 \mathrm{kcal} / \mathrm{mol}$ which is in agreement with the reported values for hydrogen bonding in the crystal structure of molecular solids, Table 3 [52,53]. Also, the $\mathrm{CH}^{\cdots} \pi$ interaction energy in compound $\mathbf{1}$ is calculated to be -15.32 $\mathrm{kcal} / \mathrm{mol}$, while that of $\pi \cdots \pi$ and $\mathrm{I} \cdots \pi$ interactions in compound 2 are -25.50 and $-17.47 \mathrm{kcal} / \mathrm{mol}$. Not surprisingly, the interaction energies of dimeric fragments containing several $\pi$-interactions and hydrogen bonds in $\mathbf{1}$ and $\mathbf{3}$ are larger than that of the fragments in which only one aromatic ring is involved in $\pi$ interactions, Tables 3 and 4, Figure S5.

\section{Conclusion}


Herein, the crystal structures of three new group IIB coordination compounds containing the 4-((pyridin4-ylmethylene)amino)phenol ligand are reported. The crystal structures of these compounds, as well as the related structures, were investigated. Geometrical analysis show the tetrahedral (1) and trigonal pyramidal ( $\mathbf{2}$ and $\mathbf{3}$ ) coordination geometry around the metal centers in these structures. It has been revealed that the $\mathbf{L}^{4-O H}$ adjust its conformation to adopt the coordination geometry requirement of the metal atom and the optimal inter-atomic distances in the supramolecular structure. The crystal structure analyses revealed that the main interactions governing the supramolecular architecture are $\pi-\pi, \mathrm{C}-\mathrm{H} \cdots \pi$, as well as $\mathrm{O}-\mathrm{H} \cdots \mathrm{N}, \mathrm{C}-\mathrm{H}^{\cdots} \mathrm{X}$ hydrogen bonding interactions. The results reported herein are useful for understanding the coordination chemistry and solid-state structure of group IIB containing Schiff-base ligands.

\author{
AUTHOR INFORMATION \\ Corresponding Authors \\ Phone: +98-21-85692619 and +98-21-82884416. \\ E-mail: t.hajiashrafi@alzahra.ac.ir
}

\title{
ACKNOWLEDGMENT.
}

We gratefully acknowledge the financial support from the Research Council of Alzahra University and Science Foundation Ireland (SFI IvP 13/IA/1894)

\section{References}

[1] J. Liu, L. Chen, H. Cui, J. Zhang, L. Zhang, C.-Y. Su, Chemical Society Reviews, 43 (2014) 60116061.

[2] M.L. Foo, R. Matsuda, S. Kitagawa, Chemistry of Materials, 26 (2014) 310-322.

[3] A.J. Blake, N.R. Champness, P. Hubberstey, W.-S. Li, M.A. Withersby, M. Schröder, Coordination Chemistry Reviews, 183 (1999) 117-138.

[4] R. Custelcean, B.A. Moyer, European Journal of Inorganic Chemistry, 2007 (2007) 1321-1340.

[5] A.K. Nangia, G.R. Desiraju, Angewandte Chemie International Edition, 58 (2019) 4100-4107.

[6] A. Pendas, S. Shaik, J.J. Novoa, A. Gavezzotti, P. Popelier, J. Contreras-Garcia, E. Arunan, R.

Gobetto, A. Bacchi, P. Politzer, Intermolecular interactions in crystals: fundamentals of crystal engineering, Royal Society of Chemistry, 2017.

[7] V.S. Pervov, A.E. Zotova, ChemPhysChem, 14 (2013) 3865-3867.

[8] I. Dance, The Crystal as a Supramolecular Entity", Desiraju, GR, Ed.; John Wiley: New York, (1996) 137-233. 
[9] T.R. Cook, Y.-R. Zheng, P.J. Stang, Chemical Reviews, 113 (2013) 734-777.

[10] L. Brammer, Chemical Society Reviews, 33 (2004) 476-489.

[11] L.F. Lindoy, K.-M. Park, S.S. Lee, Chemical Society Reviews, 42 (2013) 1713-1727.

[12] E.C. Constable, C.E. Housecroft, B.M. Kariuki, N. Kelly, C.B. Smith, Comptes Rendus Chimie, 5 (2002) 425-430.

[13] E. Pardo, R. Ruiz-Garcia, J. Cano, X. Ottenwaelder, R. Lescouezec, Y. Journaux, F. Lloret, M.

Julve, Dalton Transactions, (2008) 2780-2805.

[14] J. Fielden, D.-1. Long, A.M. Slawin, P. Kögerler, L. Cronin, Inorganic Chemistry, 46 (2007) 90909097.

[15] Z. Ni, J.J. Vittal, Crystal Growth \& Design, 1 (2001) 195-197.

[16] A.K. Gupta, D.M. Salazar, A. Orthaber, European Journal of Inorganic Chemistry, 2019 (2019) 3740-3744.

[17] P. Kanoo, G. KL, T.K. Maji, Crystal Growth \& Design, 9 (2009) 4147-4156.

[18] M. Đaković, Ž. Soldin, B.-M. Kukovec, I. Kodrin, C.B. Aakeröy, N. Baus, T. Rinkovec, IUCrJ, 5 (2018) 13-21.

[19] D. Braga, F. Grepioni, Accounts of Chemical Research, 33 (2000) 601-608.

[20] H.R. Khavasi, A. Azhdari Tehrani, Inorganic Chemistry, 52 (2013) 2891-2905.

[21] B. Cheng, A.A. Tehrani, M.-L. Hu, A. Morsali, CrystEngComm, 16 (2014) 9125-9134.

[22] A. Azhdari Tehrani, S. Abedi, A. Morsali, Crystal Growth \& Design, 17 (2017) 255-261.

[23] M.S. Deshpande, A.S. Kumbhar, V.G. Puranik, Crystal Growth \& Design, 8 (2008) 1952-1960.

[24] A.A. Eliseeva, D.M. Ivanov, A.S. Novikov, A.V. Rozhkov, I.V. Kornyakov, A.Y. Dubovtsev, V.Y. Kukushkin, Dalton Transactions, 49 (2020) 356-367.

[25] H.R. Khavasi, M. Azizpoor Fard, Crystal Growth \& Design, 10 (2010) 1892-1896.

[26] T. Hajiashrafi, A.N. Kharat, J.A. Love, B.O. Patrick, Polyhedron, 60 (2013) 30-38.

[27] H.R. Khavasi, S. Kavand, Dalton Transactions, 45 (2016) 10761-10770.

[28] H.R. Khavasi, B.M.M. Sadegh, Dalton Transactions, 43 (2014) 5564-5573.

[29] J. Reedijk, Chemical Society Reviews, 42 (2013) 1776-1783.

[30] G.R. Desiraju, Chemical Communications, (1997) 1475-1482.

[31] T. Hajiashrafi, R. Zekriazadeh, K.J. Flanagan, F. Kia, A. Bauzá, A. Frontera, M.O. Senge, Acta Crystallographica Section C: Structural Chemistry, 75 (2019) 178-188.

[32] T. Hajiashrafi, S. Salehi, M. Kubicki, A. Bauzá, A. Frontera, K.J. Flanagan, M.O. Senge,

CrystEngComm, 21 (2019) 6301-6312.

[33] T. Hajiashrafi, G.M. Ziarani, M. Kubicki, F.T. Fadaei, K.J. Schenk, Polyhedron, 119 (2016) 260266.

[34] M.A. Spackman, D. Jayatilaka, CrystEngComm, 11 (2009) 19-32.

[35] F. Neese, U. Becker, D. Ganyushin, A. Hansen, D. Liakos, C. Kollmar, S. Kossmann, T. Petrenko,

C. Reimann, C. Riplinger, Neese, F., Wennmohs, F., Becker, U., Bykov, D., Ganyushin, D., Hansen, A., ... \& Pantazis, D. A. (2014). ORCA, version 3.0. Max Planck Institute for Chemical Energy Conversion, Mülheim/Ruhr, Germany.

[36] A.D. Becke, Physical review A, 38 (1988) 3098.

[37] S. Grimme, J. Antony, S. Ehrlich, H. Krieg, The Journal of Chemical Physics, 132 (2010) 154104.

[38] C. Fonseca Guerra, H. Zijlstra, G. Paragi, F.M. Bickelhaupt, Chemistry-A European Journal, 17

(2011) 12612-12622.

[39] D. Sadhukhan, M. Maiti, G. Pilet, A. Bauzá, A. Frontera, S. Mitra, European Journal of Inorganic Chemistry, 2015 (2015) 1958-1972.

[40] A.A. Tehrani, H. Ghasempour, A. Morsali, A. Bauzá, A. Frontera, P. Retailleau, CrystEngComm, 19 (2017) 1974-1981. 
[41] P. Chakraborty, S. Purkait, S. Mondal, A. Bauzá, A. Frontera, C. Massera, D. Das, CrystEngComm, 17 (2015) 4680-4690.

[42] L. Yang, D.R. Powell, R.P. Houser, Dalton Transactions, (2007) 955-964.

[43] D. Liu, J.-P. Lang, B.F. Abrahams, Chemical Communications, 49 (2013) 2682-2684.

[44] C.-Y. Nie, Y.-P. Tian, Acta Crystallographica Section E: Structure Reports Online, 69 (2013)

m135-m135.

[45] L.-Y. Xu, H.-X. Chen, X.-J. Sun, P.-Y. Gu, J.-F. Ge, N.-J. Li, Q.-F. Xu, J.-M. Lu, Polyhedron, 35 (2012) 7-14.

[46] Y. Xu, W. Li, J. Wu, H. Zhou, J. Yang, S. Li, Y. Tian, Chinese Journal of Inorganic Chemistry, 26 (2010) 997-1002.

[47] Cambridge Structural Database, CCDC, Cambridge, U.K., November 2017.

[48] A.A. Tehrani, A. Morsali, M. Kubicki, Dalton Transactions, 44 (2015) 5703-5712.

[49] T. Hajiashrafi, A. Morsali, M. Kubicki, Polyhedron, 100 (2015) 257-263.

[50] J.J. McKinnon, D. Jayatilaka, M.A. Spackman, Chemical Communications, (2007) 3814-3816.

[51] O. Amelines-Sarria, V.A. Basiuk, V. Duarte-Alaniz, M. Rivera, Physical Chemistry Chemical

Physics, 17 (2015) 27399-27408.

[52] X. Qian, D.K. Johnson, M.E. Himmel, M.R. Nimlos, Carbohydrate Research, 345 (2010) 19451951.

[53] S. Saha, A. Sasmal, C.R. Choudhury, G. Pilet, A. Bauzá, A. Frontera, S. Chakraborty, S. Mitra, Inorganica Chimica Acta, 425 (2015) 211-220.

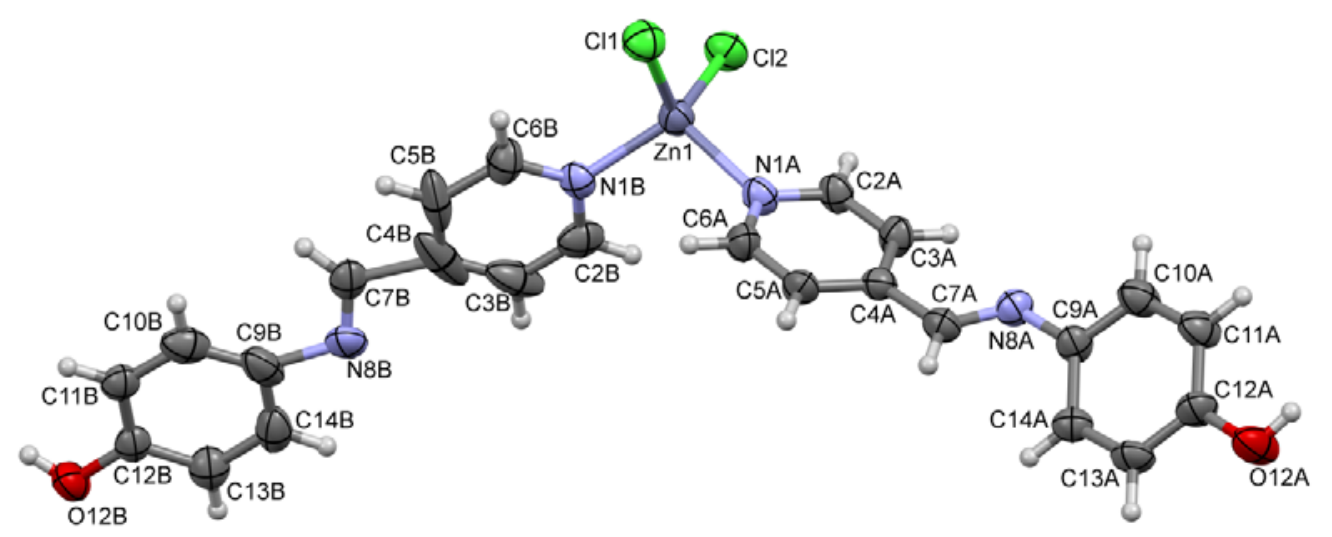

(a) 


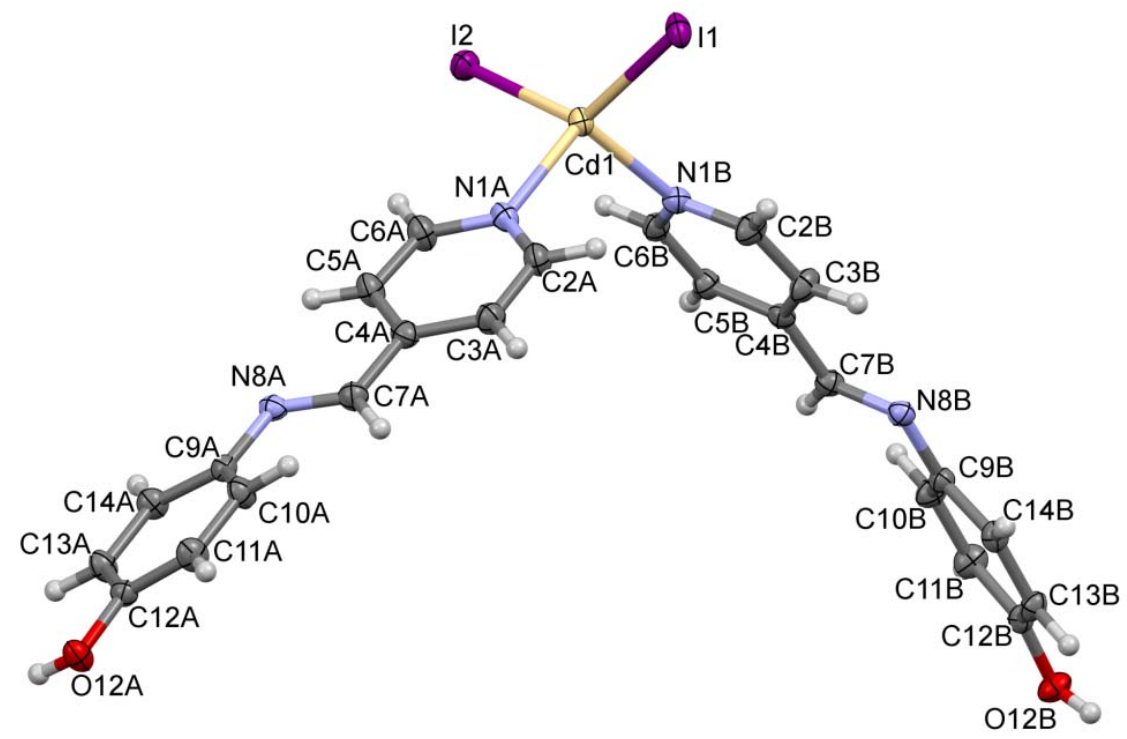

(b)

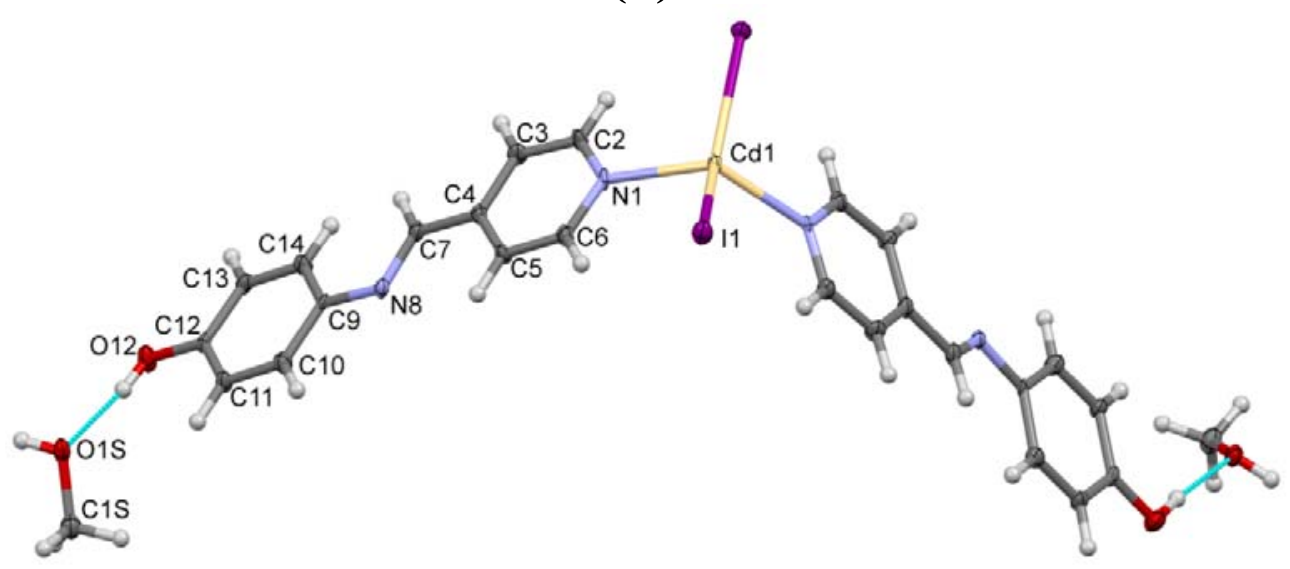

(c)

Figure 1. ORTEP diagram of compounds 1 (a), 2 (b), and 3 (c), drawn at 50\% probability ellipsoids 


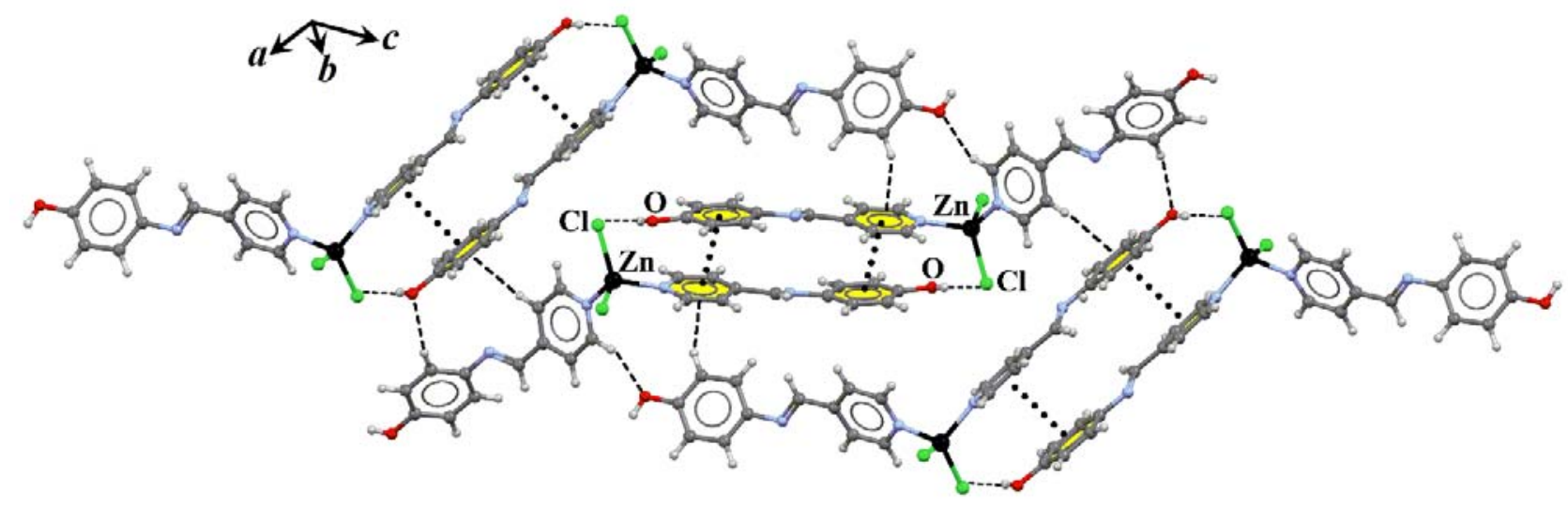

Figure 2. Representation of the crystal packing of compound 1 showing the association of molecular units through a combination of $\pi-\pi$ stacking $\mathrm{C}-\mathrm{H} \bullet \bullet \pi$, as well as $\mathrm{C}-\mathrm{H} \bullet \bullet \mathrm{O}$ non-classical hydrogen bonds in the crystallographic $b$-direction.

The overall supramolecular structure results from linking the $\left[\mathrm{Zn}(\mathrm{L})_{2} \mathrm{Cl}_{2}\right]$ units via $\mathrm{C}-\mathrm{H} \cdots \cdot \mathrm{Cl}, \mathrm{O}-\mathrm{H} \cdots \mathrm{Cl}$ and $\mathrm{C}-\mathrm{H} \cdots \pi$ interactions in the $a c$-plane. 


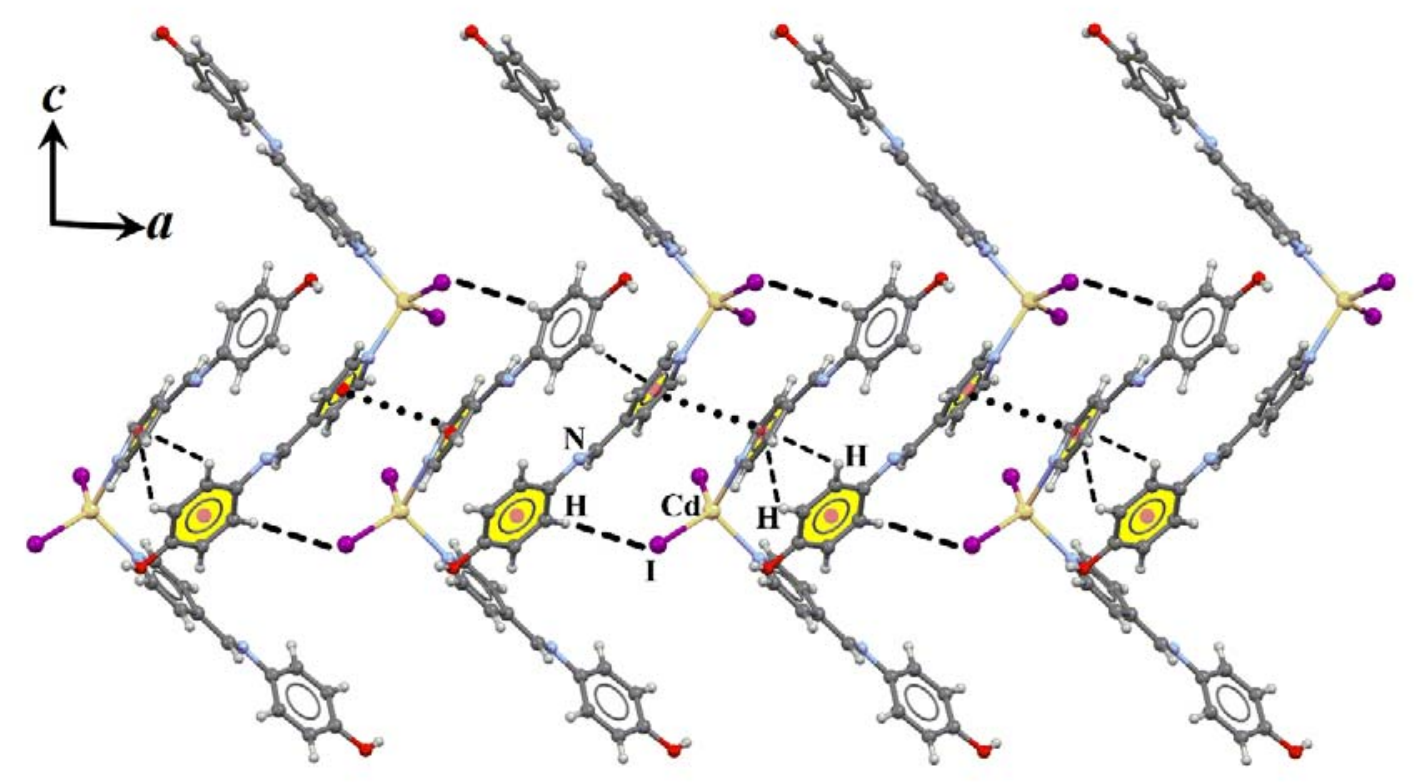

(a)

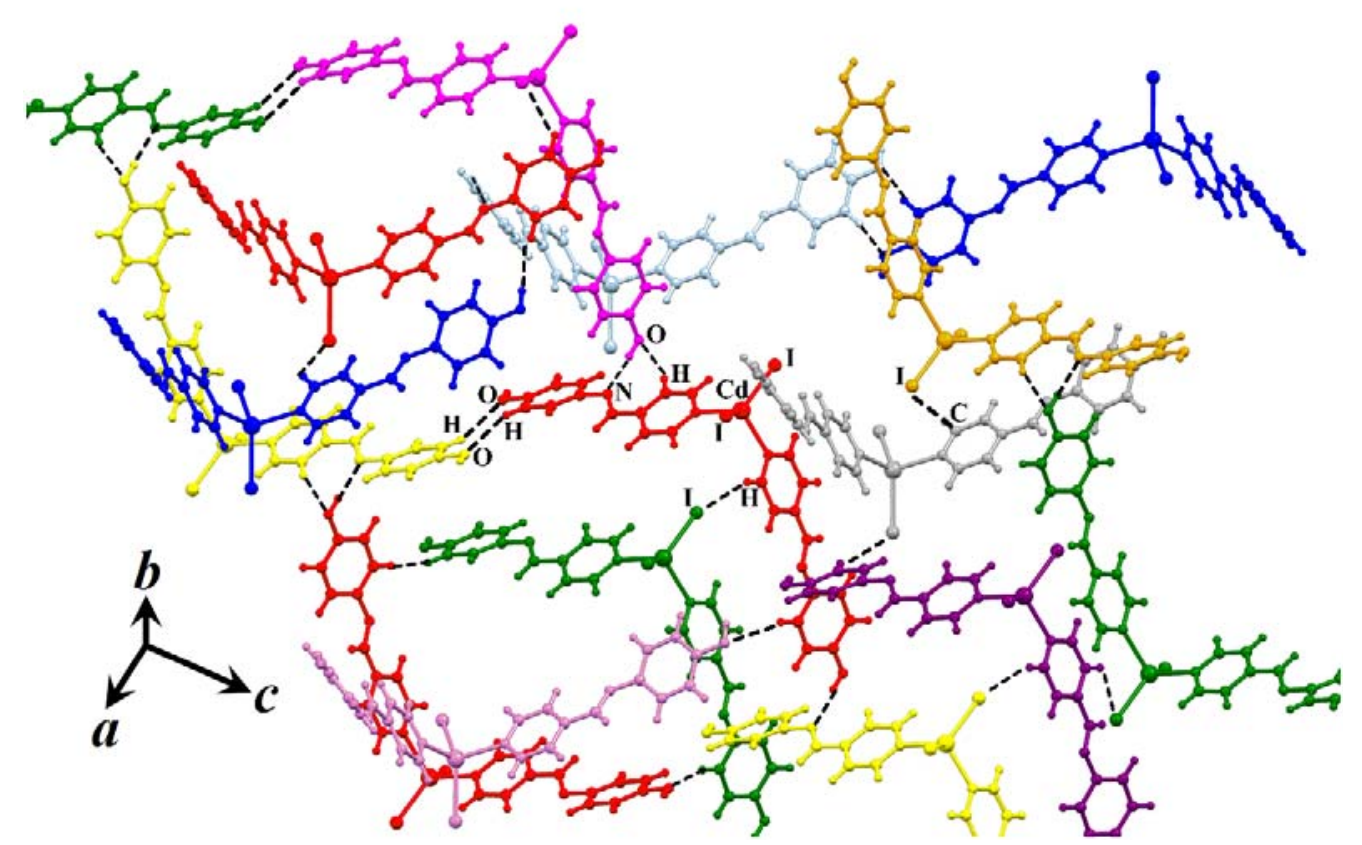

(b)

Figure 3. Representation of the crystal packing of compound $\mathbf{2}$ showing the supramolecular association of discrete molecular units along the crystallographic $a$-direction through $\pi-\pi$ stacking, C-H $\cdots \pi$ and I $\cdots \pi$ interactions (a) View showing the three-dimensional crystal packing; the $\mathrm{O}-\mathrm{H} \cdots \mathrm{N}, \mathrm{R}_{2}{ }^{2}(8) \mathrm{C}-\mathrm{H} \cdots \mathrm{O}$ and $\mathrm{C}-\mathrm{H} \cdots \mathrm{I}$ hydrogen bonds link these units in the $b c-$ plane (b). 


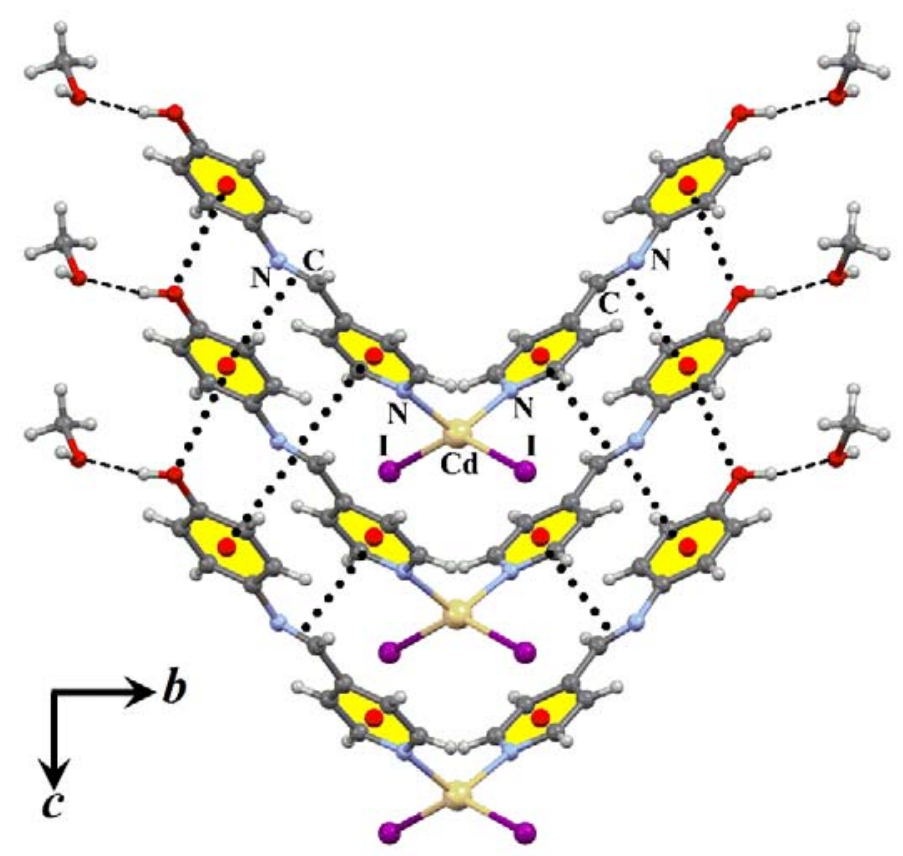

(a)

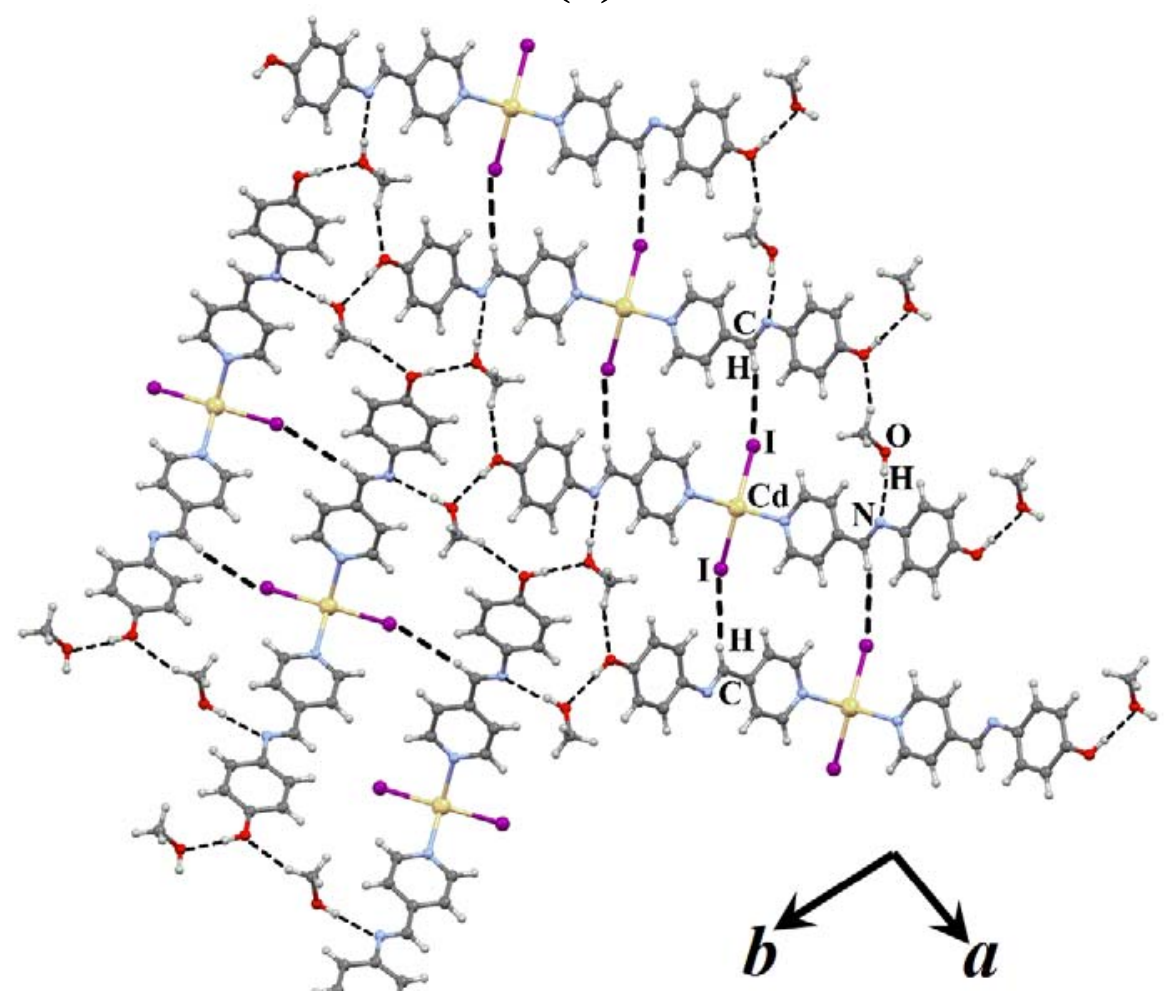

(b)

Figure 4. Representation of the crystal packing of compound 3 showing the supramolecular association of discrete molecular units imine $\pi-\pi_{\text {phenyl, imine }} \pi-\pi_{\text {pyridyl }}$, O(lone pair) $\cdots \pi_{\text {phenyl }}$ interactions along the crystallographic $c$-direction (a) View showing the three-dimensional crystal packing; the methanol molecules of crystallization link discrete molecular units, in the $a b$-plane, via ${ }_{\mathrm{MeOH}} \mathrm{O}-\mathrm{H} \bullet \bullet \mathrm{N}_{\text {imine }}$ and ${ }_{\mathrm{MeOH}} \mathrm{C}-\mathrm{H} \bullet \bullet \mathrm{O}_{\mathrm{OH}}$ hydrogen bonds, which is further assisted by ${ }_{\text {imine }} \mathrm{C}-\mathrm{H} \bullet \bullet \cdot \mathrm{I}$ interaction (b) 


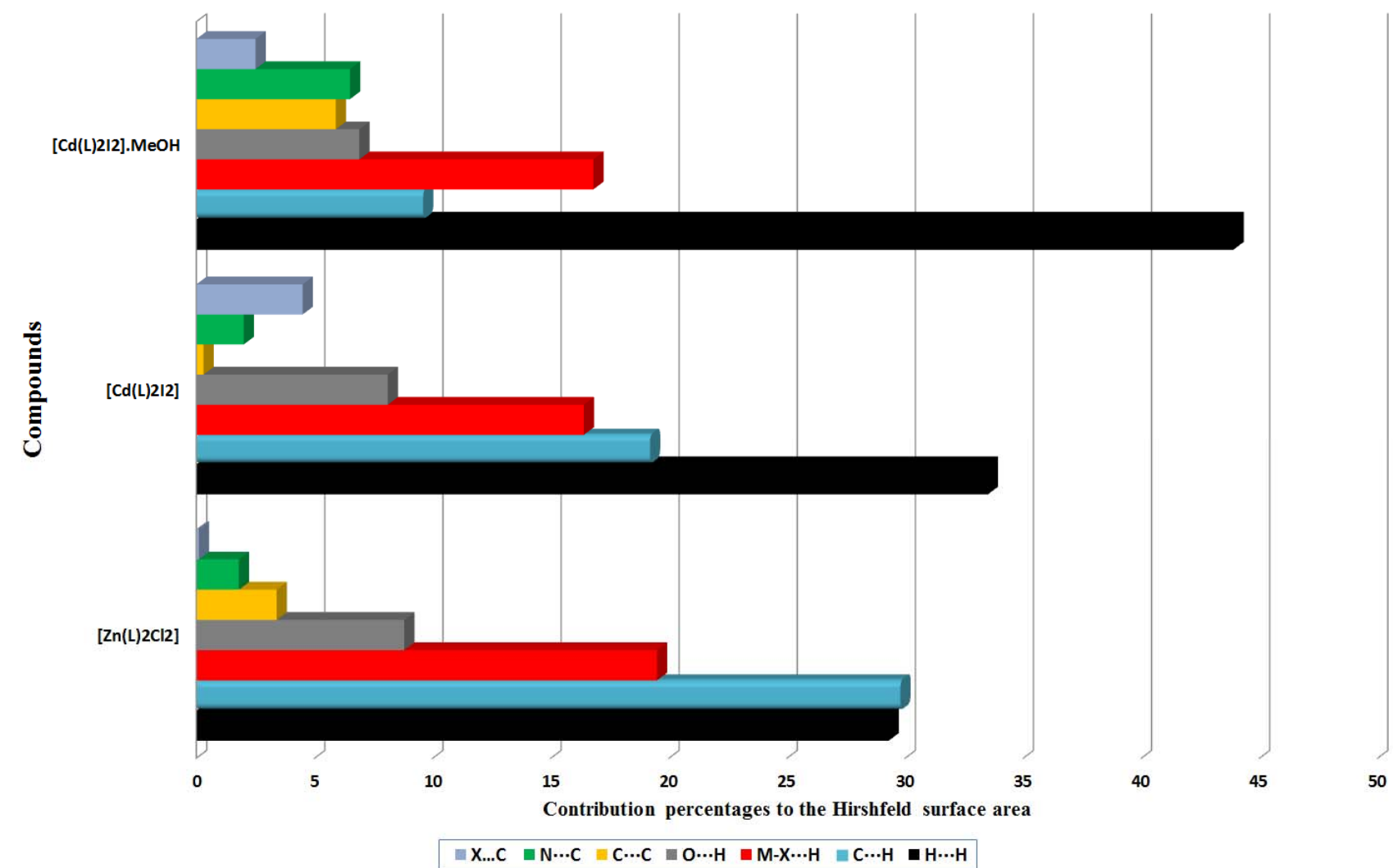

Figure 5. Horizontal bar chart showing the relative contributions of different intermolecular interactions to the Hirshfeld surface areas in compounds $\mathbf{1}-\mathbf{3}$. 
Table 1. Structural data and refinement parameters for compounds 1-3.

\begin{tabular}{|c|c|c|c|}
\hline & 1 & 2 & 3 \\
\hline formula & $\mathrm{C}_{24} \mathrm{H}_{20} \mathrm{Zn} \mathrm{Cl}{ }_{2} \mathrm{~N}_{4} \mathrm{O}_{2}$ & $\mathrm{C}_{24} \mathrm{H}_{20} \mathrm{CdI}_{2} \mathrm{~N}_{4} \mathrm{O}_{2}$ & $\mathrm{C}_{26} \mathrm{H}_{28} \mathrm{CdI}_{2} \mathrm{~N}_{4} \mathrm{O}_{4}$ \\
\hline fw & 532.71 & 762.6 & 826.72 \\
\hline$\lambda / \AA$ & 0.71073 & 0.71073 & 0.71073 \\
\hline$T / \mathrm{K}$ & $130(1)$ & $100(1)$ & $100(1)$ \\
\hline crystal system & Monoclinic & Monoclinic & Orthorhombic \\
\hline space group & $P 2{ }_{1} / n$ & $I 2 / a$ & Pba2 \\
\hline$a / \AA$ & $9.3689(6)$ & $10.5408(3)$ & $9.1610(13)$ \\
\hline$b / \AA$ & $12.9152(7)$ & $19.3211(4)$ & $32.257(4)$ \\
\hline$c / \AA$ & $19.1424(13)$ & $25.6456(7)$ & $4.7290(7)$ \\
\hline$\alpha /^{\circ}$ & 90 & 90 & 90 \\
\hline$\beta /^{\circ}$ & $93.373(6)$ & $91.511(2)$ & 90 \\
\hline$\gamma /{ }^{\circ}$ & 90 & 90 & 90 \\
\hline$V / \AA^{3}$ & $2312.2(2)$ & $5221.2(2)$ & 1397.4(3) \\
\hline$D_{\text {calc }} / \mathrm{Mg} \cdot \mathrm{m}^{-3}$ & 1.530 & 1.940 & 1.965 \\
\hline$Z$ & 4 & 8 & 2 \\
\hline$\mu\left(\mathrm{mm}^{-1}\right)$ & 3.847 & 3.229 & 3.029 \\
\hline$F(000)$ & 1088 & 2896 & 796 \\
\hline $2 \theta\left(^{\circ}\right)$ & 65.5 & 50.0 & 55.1 \\
\hline$R$ (int) & 0.2152 & 0.0264 & 0.0604 \\
\hline GOOF & 0.968 & 1.052 & 1.131 \\
\hline $\mathrm{R}_{1}^{a}(\mathrm{I}>2 \sigma(\mathrm{I}))$ & 0.0641 & 0.0174 & 0.0284 \\
\hline$w \mathrm{R}_{2}^{b}(\mathrm{I}>2 \sigma(\mathrm{I}))$ & 0.1249 & 0.0389 & 0.0678 \\
\hline CCDC No. & 1993550 & 1993551 & 1993552 \\
\hline
\end{tabular}


Table 2. Selected bond distances $(\AA)$ and angles $\left(^{\circ}\right)$ for complexes 1-3.

\begin{tabular}{ccccc}
\hline & & \multicolumn{3}{c}{ Complex } \\
\cline { 3 - 5 } & & $\mathbf{1}$ & $\mathbf{2}$ & $\mathbf{3}$ \\
\hline \multirow{3}{*}{ Bond } & M1-N1A & $2.032(4)$ & $2.293(2)$ & $2.290(1)$ \\
distance & M1-N1B & $2.019(4)$ & $2.283(2)$ & $2.290(1)$ \\
& M1-X1 & $2.234(2)$ & $2.6932(5)$ & $2.7304(2)$ \\
& M1-X2 & $2.228(2)$ & $2.7117(6)$ & $2.7304(2)$ \\
\hline \multirow{5}{*}{ Bond } & N1A-M1-N1B & $107.5(2)$ & $107.19(6)$ & $119.8(1)$ \\
angle & X1-M1-X2 & $114.75(7)$ & $129.33(2)$ & $137.48(1)$ \\
& N1A-M1-X1 & $107.1(1)$ & $105.77(5)$ & $99.4(2)$ \\
& N1A-M1-X2 & $108.1(1)$ & $104.00(5)$ & $101.5(1)$ \\
& N1B-M1-X1 & $106.1(1)$ & $105.18(5)$ & $99.4(2)$ \\
& N1B-M1-X2 & $112.9(1)$ & $103.87(5)$ & $101.5(1)$ \\
\hline
\end{tabular}


Table 3. Selected hydrogen bond geometries for coordination compounds 1-3

\begin{tabular}{|c|c|c|c|c|c|c|c|}
\hline Compound & D-H $\cdots A$ & $\mathbf{d}(\mathbf{D}-\mathrm{H}) / \AA$ & $\mathbf{d}(\mathbf{H} \cdots \mathbf{A}) / \AA$ & $\mathbf{d}(\mathbf{D} \cdots \mathbf{A}) / \AA$ & $<\mathrm{D}-\mathrm{H} \cdot \cdots \mathbf{A} /^{\circ}$ & Binding Energy (kcal/mol) & Sym. Code \\
\hline \multirow{6}{*}{1} & O12A-H12A $\cdots \mathrm{Cl1}$ & 0.840 & $2.331(1)$ & $3.127(5)$ & $158.1(1)$ & $-29.75^{\mathrm{I}}$ & $-x, 1-y, 1-z$ \\
\hline & $\mathrm{O} 12 \mathrm{~B}-\mathrm{H} 12 \mathrm{~B} \cdots \mathrm{Cl} 2$ & 0.840 & $2.312(1)$ & $3.135(4)$ & $167.2(1)$ & $-33.78^{\mathrm{II}}$ & $2-x, 1-y,-z$ \\
\hline & C7B-H7B $\cdots \mathrm{Cl1}$ & 0.950 & $2.916(1)$ & $3.85(2)$ & $169.0(1)$ & \multirow{4}{*}{-20.25} & $1-x, 1-y,-z$ \\
\hline & C10B-H10B $\cdots \mathrm{Cl} 1$ & 0.95 & $3.145(3)$ & $4.022(7)$ & $154.5(2)$ & & $1-x, 1-y,-z$ \\
\hline & C10A-H10A $\cdots$ O12B & 0.950 & $2.618(2)$ & $3.538(8)$ & $162.9(1)$ & & $1.5-\mathrm{x},-1 / 2+\mathrm{y}, 1 / 2-\mathrm{z}$ \\
\hline & C6A-H6A $\cdots \mathrm{O} 12 \mathrm{~A}$ & 0.950 & $2.453(2)$ & $3.083(8)$ & $123.7(2)$ & & $1 / 2+x, 1 / 2-y,-1 / 2+z$ \\
\hline \multirow{9}{*}{2} & O12A-H12A $\cdots$ N8B & 0.840 & $1.990(1)$ & $2.828(2)$ & $175.0(1)$ & \multirow{3}{*}{-10.20} & $1 / 2+x, 1 / 2+y,-1 / 2+z$ \\
\hline & O12B-H12B $\cdots$ N8A & 0.840 & $1.964(2)$ & $2.803(2)$ & $177.7(2)$ & & $1 / 2+x,-1 / 2+y, 1 / 2+z$ \\
\hline & C13A-H13A $\cdots$ N8B & 0.950 & $2.651(2)$ & $3.363(3)$ & $132.1(1)$ & & $1 / 2+x, 1 / 2+y,-1 / 2+z$ \\
\hline & C13A-H13A $\cdots$ I1 & 0.950 & $3.1065(1)$ & $3.837(2)$ & $135.0(2)$ & \multirow[t]{2}{*}{-7.32} & $1-x, 1 / 2+y, 1 / 2-z$ \\
\hline & C11A-H11A $\cdots$ O12A & 0.950 & $2.618(3)$ & $3.522(3)$ & $159.1(2)$ & & $2-x, 1-y,-z$ \\
\hline & C14A-H14A $\cdots$ O12B & 0.950 & $2.716(2)$ & $3.327(3)$ & $122.6(2)$ & \multirow{4}{*}{-3.20} & $-1 / 2+x, 1 / 2+y,-1 / 2+z$ \\
\hline & C14B-H14B $\cdots \mathrm{O} 12 \mathrm{~A}$ & 0.950 & $2.696(3)$ & $3.286(3)$ & $120.9(1)$ & & $2-x,-1 / 2+y, 1 / 2-z$ \\
\hline & C11A-H11A $\cdots$ O15A & 0.950 & $2.511(1)$ & $3.404(3)$ & $156.7(1)$ & & $-1 / 2+x, 1 / 2+y,-1 / 2+z$ \\
\hline & C3B-H3B $\cdots \mathrm{O} 12 \mathrm{~A}$ & 0.950 & $2.712(3)$ & $3.571(3)$ & $150.8(1)$ & & $-1 / 2+x,-1 / 2+y, 1 / 2+z$ \\
\hline \multirow{6}{*}{3} & 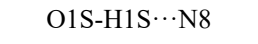 & 0.840 & $2.012(1)$ & $2.848(6)$ & $172.5(1)$ & \multirow{6}{*}{-5.34} & $1 / 2+x, 1 / 2-y, 1 / 2+z$ \\
\hline & $\mathrm{O} 12-\mathrm{H} 12 \cdots \mathrm{O} 1 \mathrm{~S}$ & 0.840 & $1.841(3)$ & $2.677(6)$ & $172.9(2)$ & & $\mathrm{x}, \mathrm{y}, \mathrm{z}$ \\
\hline & $\mathrm{C} 11-\mathrm{H} 11 \cdots \mathrm{O} 12$ & 0.950 & $2.579(3)$ & $3.314(8)$ & $134.4(1)$ & & $-1 / 2+x, 1 / 2-y, z$ \\
\hline & C7-H7 $\cdots$ I1 & 0.950 & $3.1568(2)$ & $4.064(6)$ & $160.3(1)$ & & 1-x,1-y,1-z \\
\hline & C5-H5 $\cdots$ O1S & 0.950 & $2.423(1)$ & $3.341(7)$ & $162.5(1)$ & & $1 / 2+x, 1 / 2-y, 1+z$ \\
\hline & $\mathrm{C} 10-\mathrm{H} 10 \cdots \mathrm{O} 1 \mathrm{~S}$ & 0.950 & $2.585(1)$ & $3.354(8)$ & $138.2(1)$ & & $1 / 2+x, 1 / 2-y, 1+z$ \\
\hline
\end{tabular}

Table 4. $\pi$-interactions for compounds 1-3

\begin{tabular}{|c|c|c|c|c|c|c|c|c|}
\hline \multirow[b]{2}{*}{ Compound } & \multirow[b]{2}{*}{ Interaction } & \multirow[b]{2}{*}{ C-H/atom $\cdots \pi$} & \multicolumn{4}{|c|}{$\pi \cdots \pi$} & \multirow[b]{2}{*}{$\begin{array}{c}\text { Binding } \\
\text { energy } \\
(\mathrm{kcal} / \mathrm{mol})\end{array}$} & \multirow[b]{2}{*}{ Sym. code } \\
\hline & & & $\begin{array}{c}\mathbf{d}_{\text {cg-cg }} \\
(\AA)\end{array}$ & $\begin{array}{c}\text { Offset } \\
\text { angle } \\
\left(^{\circ}\right)\end{array}$ & $\begin{array}{c}\text { plane } \\
\text { to } \\
\text { plane } \\
\text { angle } \\
\left({ }^{\circ}\right)\end{array}$ & $\mathbf{d}_{\text {offset }}(\AA)$ & & \\
\hline \multirow{5}{*}{1} & C11A-H11A $\cdots \pi_{\text {pyridyl(N1A-C6A) }}$ & $2.834(1)$ & - & - & - & - & $-29.75^{1}$ & $-x, 1-y, 1-z$ \\
\hline & C2B-H2B $\cdots \pi_{\text {phenyl(C9A-C14A) }}$ & $2.638(1)$ & & & & & -15.32 & $-x, 1-y, 1-z$ \\
\hline & C3A-H3A $\cdots \pi_{\text {phenyl(C9B-C14B) }}$ & $2.817(2)$ & & & & & & $2-x, 1-y,-z$ \\
\hline & C13A-H13A $\cdots \pi_{\text {pyridyl(N1B-C6B) }}$ & $2.922(3)$ & & & & & & $1 / 2+x, 1 / 2-y,-1 / 2+z$ \\
\hline & (N1B-C6B)pyridyl $\pi \cdots \pi_{\text {phenyl(C9B-C14B) }}$ & - & $3.753(2)$ & 19.58 & 5.88 & 1.25 & $-33.78^{\mathrm{II}}$ & $2-x, 1-y,-z$ \\
\hline \multirow{3}{*}{2} & (N1B-C6B)pyridyl $\pi \cdots \pi_{\text {pyridyl(N1B-C6B) }}$ & - & $3.975(2)$ & 18.39 & 24.45 & 1.28 & -25.50 & $1 / 2-x, y, 1-z$ \\
\hline & C3B-H3B $\cdots \pi_{\text {phenyl(C9B-C14B) }}$ & $3.161(1)$ & & & & & & $1.5-\mathrm{x}, \mathrm{y}, 1-\mathrm{z}$ \\
\hline & $\mathrm{I} \cdots \pi_{\text {pyridyl(N1B-C6B) }}$ & $3.875(2)$ & & & & & -17.47 & $-1 / 2+x, 1-y, z$ \\
\hline \multirow{3}{*}{3} & $\mathrm{O}($ lone pair $) \cdots \pi_{\text {phenyl }}$ & $3.488(2)$ & - & - & - & - & \multirow{3}{*}{$-36.32^{\mathrm{III}}$} & $\mathrm{x}, \mathrm{y},-1+\mathrm{z}$ \\
\hline & imine $\pi \cdots \pi_{\text {phenyl(N1-C6) }}$ & $3.497(2)$ & - & - & - & - & & $\mathrm{x}, \mathrm{y},-1+\mathrm{z}$ \\
\hline & imine $\pi \cdots \pi_{\text {phenyl(C9-C14) }}$ & $3.355(1)$ & - & - & - & - & & $\mathrm{x}, \mathrm{y},-1+\mathrm{z}$ \\
\hline
\end{tabular}

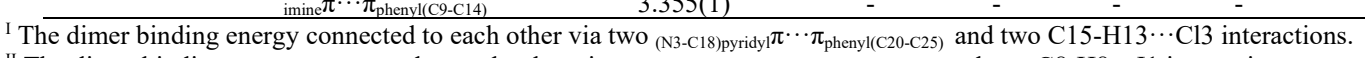

II The dimer binding energy connected to each other via two ${ }_{(\mathrm{N} 2-\mathrm{C} 13) \text { pyridy }} \pi \cdots \pi_{\text {phenyl(C2-C7) }}$ and two C8-H8 $\cdots$ I1 interactions.

${ }^{\text {III }}$ The dimer binding energy connected to each other via two sets of ${ }_{\text {imine }} \pi \cdots \pi_{\text {phenyl(N1-C6), imine }} \pi \pi_{\text {phenyl(C9-Cl4) }}$ and $\mathrm{O}($ lone pair) $\cdots \pi$ interactions. 
Table 5. Molecular features of coordination compounds containing (4-substituted)-1-(pyridin-4-yl)methanimine ligand

\begin{tabular}{|c|c|c|c|c|}
\hline Ref Code & Space group & Metal atom coordination geometry & Molecular structure & Reference \\
\hline- & $I 2 / a$ & 4-coordinate tetrahedral & Discrete coordination complex & This work \\
\hline- & $P 2_{1} / a$ & 4-coordinate trigonal pyramidal & Discrete coordination complex & This work \\
\hline- & $P b a 2$ & 4-coordinate trigonal pyramidal & Discrete coordination complex & This work \\
\hline KOWWEB & $I 2 / a$ & 6-coordnate octahedral & 1D coordination polymer & [32] \\
\hline KOWWIF & $P b a 2$ & 4-coordinate seesaw & Discrete coordination complex & [32] \\
\hline KOWWOL & $P b a 2$ & 4-coordinate seesaw & Discrete coordination complex & [32] \\
\hline ZUNSUY & $P 2_{1} / c$ & 6-coordnate octahedral & 1D coordination polymer & [49] \\
\hline HOYLIS & $P_{\overline{1}}$ & 5-coordinate square pyramidal & 1D coordination polymer & [48] \\
\hline HOYLOY & $P 2{ }_{1} 2_{1} 2_{1}$ & 4-coordinate seesaw & 1D coordination polymer & [48] \\
\hline HOYLUE & $F d d 2$ & 4-coordinate seesaw & Discrete coordination complex & [48] \\
\hline HOYMAL & $P 2_{1} / c$ & 5-coordinate square pyramidal & 1D coordination polymer & [48] \\
\hline HOYMEP & $F d d 2$ & 4-coordinate seesaw & 1D coordination polymer & {$[48]$} \\
\hline HOYMIT & $P 2_{1} 2_{1} 2_{1}$ & 4-coordinate seesaw & 1D coordination polymer & {$[48]$} \\
\hline HOYMOZ & $\operatorname{Pna}_{1}$ & 4-coordinate seesaw & 1D coordination polymer & {$[48]$} \\
\hline HOYMUF & $P 2_{1} / c$ & 4-coordinate seesaw & 1D coordination polymer & [48] \\
\hline ZUNTAF & $C 2 / c$ & 6-coordnate octahedral & 1D coordination polymer & [49] \\
\hline
\end{tabular}

